Acta Crystallographica Section B

Structural

Science

ISSN 0108-7681

\section{Ľubomír Smrčok, ${ }^{\text {a* }}$ Mariana Sládkovičová, ${ }^{a}$ Vratislav Langer, ${ }^{b}$ Chick C. Wilson ${ }^{\mathrm{c}}$ and Miroslav Koóśd}

anstitute of Inorganic Chemistry, Slovak Academy of Sciences, Dúbravská cesta 9 , SK-845 36 Bratislava, Slovakia, benvironmental Inorganic Chemistry, Department of Chemical and Biological Engineering, Chalmers University of Technology, SE-412 96 Göteborg, Sweden, 'Department of Chemistry and WestCHEM Research School, University of Glasgow, Glasgow G12 8QQ, Scotland, and Institute of Chemistry, Slovak Academy of Sciences, Dúbravská cesta 9, SK-845 38 Bratislava, Slovakia

Correspondence e-mail: uachsmrk@savba.sk
(C) 2006 International Union of Crystallography Printed in Great Britain - all rights reserved

\title{
On hydrogen bonding in 1,6-anhydro- $\beta$-D-gluco- pyranose (levoglucosan): X-ray and neutron diffraction and DFT study
}

The geometry of hydrogen bonds in 1,6-anhydro- $\beta$-D-glucopyranose (levoglucosan) is accurately determined by refinement of time-of-flight neutron single-crystal diffraction data. Molecules of levoglucosan are held together by a hydrogenbond array formed by a combination of strong $\mathrm{O}-\mathrm{H} \cdots \mathrm{O}$ and supporting weaker $\mathrm{C}-\mathrm{H} \cdots \mathrm{O}$ bonds. These are fully and accurately detailed by the neutron diffraction study. The strong hydrogen bonds link molecules in finite chains, with hydroxyl $\mathrm{O}$ atoms acting as both donors and acceptors of hydroxyl $\mathrm{H}$ atoms. A comparison of molecular and solid-state DFT calculations predicts red shifts of $\mathrm{O}-\mathrm{H}$ and associated blue shifts of $\mathrm{C}-\mathrm{H}$ stretching frequencies due to the formation of hydrogen bonds in this system.

\section{Introduction}

Hydrogen bonding is probably the most important intermolecular interaction in nature, being involved in the structure and properties of various compounds ranging from water to proteins. The study reported here is part of a recently initiated project focused on obtaining an accurate description of hydrogen bonding in selected compounds using a combination of diffraction methods and quantum chemistry calculations, both isolated molecule and solid-state. Neutron diffraction studies are used in this programme with the aim of providing accurate data on the positions and geometries of $\mathrm{H}$ atoms in the systems under study. This approach allows full specification of hydrogen-bond geometry and a correlation with parallel quantum calculation and spectroscopic observations. The title material, levoglucosan, is an ideal candidate compound for such a study, as it has a crystal structure containing relatively strong $\mathrm{O}-\mathrm{H} \cdots \mathrm{O}$ hydrogen bonds coexisting with weaker $\mathrm{C}-\mathrm{H} \cdots \mathrm{O}$ interactions, providing an opportunity to examine cooperation or competition between these interactions.

The crystal structure of levoglucosan was first described by Park et al. (1971). This original X-ray diffraction structure determination was carried out at room temperature using $\mathrm{Cu} \mathrm{K \alpha}$ radiation. The refinement included only non- $\mathrm{H}$-atom parameters; the positions of $\mathrm{H}$ atoms were only estimated approximately from a difference-Fourier synthesis. Because of these limitations, only basic information on the $X-\mathrm{H} \cdots \mathrm{O}$ bond geometries was obtained; as a result, only strong $\mathrm{O}-$ $\mathrm{H}$. O O bonds were discussed in detail and the determination lacked detailed consideration of the $\mathrm{H}$-atom behaviour.

The aim of the present study is to provide a full and accurate description of the hydrogen bonds in the structure of levoglucosan by making use of low-temperature neutron time-
Received 24 April 2006 Accepted 28 June 2006 
Table 1

Experimental details.

\begin{tabular}{|c|c|c|}
\hline & X-ray & Time-of-flight neutron \\
\hline \multicolumn{3}{|l|}{ Crystal data } \\
\hline Chemical formula & $\mathrm{C}_{6} \mathrm{H}_{10} \mathrm{O}_{5}$ & $\mathrm{C}_{6} \mathrm{H}_{10} \mathrm{O}_{5}$ \\
\hline$M_{r}$ & 162.14 & 162.14 \\
\hline $\begin{array}{l}\text { Cell setting, space } \\
\text { group }\end{array}$ & Orthorhombic, $P 2_{1} 2_{1} 2_{1}$ & Orthorhombic, $P 2_{1} 2_{1} 2_{1}$ \\
\hline Temperature (K) & $173(2)$ & $100(1)$ \\
\hline$a, b, c(\AA)$ & $\begin{array}{l}6.6614(1), 13.3104(2) \\
\quad 7.4914(1)\end{array}$ & $\begin{array}{l}6.6560(1), 13.3140(2), \\
\quad 7.4680(1)\end{array}$ \\
\hline$V\left(\AA^{3}\right)$ & $664.23(2)$ & $661.80(2)$ \\
\hline$Z$ & 4 & 4 \\
\hline$D_{x}\left(\mathrm{Mg} \mathrm{m}^{-3}\right)$ & 1.621 & 1.627 \\
\hline Radiation type & Mo $K \alpha$ & Neutron \\
\hline$\mu\left(\mathrm{mm}^{-1}\right)$ & 0.14 & 2.38 \\
\hline Crystal form, colour & Block, colourless & $\begin{array}{l}\text { Irregular prism, } \\
\text { colourless }\end{array}$ \\
\hline Crystal size $(\mathrm{mm})$ & $1.35 \times 0.70 \times 0.40$ & $3 \times 2 \times 2$ \\
\hline \multicolumn{3}{|l|}{ Data collection } \\
\hline Diffractometer & $\begin{array}{l}\text { Siemens SMART 1K } \\
\text { CCD area detector }\end{array}$ & SXD \\
\hline Data collection method & $\omega$ scans & $\begin{array}{l}\text { Time-of-flight Laue } \\
\text { diffraction }\end{array}$ \\
\hline Absorption correction & $\begin{array}{l}\text { Multi-scan (based on } \\
\text { symmetry-related } \\
\text { measurements) }\end{array}$ & $\begin{array}{l}\text { Empirical (using } \\
\text { intensity } \\
\text { measurements) }\end{array}$ \\
\hline$T_{\min }$ & 0.830 & 0.29 \\
\hline$T_{\max }$ & 0.945 & 0.67 \\
\hline $\begin{array}{l}\text { No. of measured, } \\
\text { independent and } \\
\text { observed reflections }\end{array}$ & $11258,1401,1265$ & $12381,2189,2186$ \\
\hline $\begin{array}{l}\text { Criterion for observed } \\
\text { reflections }\end{array}$ & $I>2 \sigma(I)$ & $I>2 \sigma(I)$ \\
\hline$R_{\text {int }}$ & 0.042 & 0.081 \\
\hline$\theta_{\max }\left({ }^{\circ}\right)$ & 32.8 & - \\
\hline \multicolumn{3}{|l|}{ Refinement } \\
\hline Refinement on & $F^{2}$ & $F^{2}$ \\
\hline $\begin{array}{c}R\left[F^{2}>2 \sigma\left(F^{2}\right)\right] \\
w R\left(F^{2}\right), S\end{array}$ & $0.032,0.083,1.02$ & $0.070,0.181,1.21$ \\
\hline No. of reflections & 2370 & 2189 \\
\hline No. of parameters & 113 & 190 \\
\hline $\mathrm{H}$-atom treatment & $\begin{array}{l}\text { Constrained to parent } \\
\text { site }\end{array}$ & Refined independently \\
\hline Weighting scheme & $\begin{array}{l}w=1 /\left[\sigma^{2}\left(F_{o}^{2}\right)+\right. \\
\left.\quad(0.050 P)^{2}+0.0743 P\right] \\
\quad \text { where } P=\left(F_{o}^{2}+\right. \\
\left.2 F_{c}^{2}\right) / 3\end{array}$ & $\begin{array}{l}w=1 /\left[\sigma^{2}\left(F_{o}^{2}\right)+\right. \\
\quad(0.0431 P)^{2}+ \\
\quad 0.2449 P], \text { where } P= \\
\left(F_{o}^{2}+2 F_{c}^{2}\right) / 3\end{array}$ \\
\hline$(\Delta / \sigma)_{\max }$ & $<0.0001$ & $<0.0001$ \\
\hline$\Delta \rho_{\max }, \Delta \rho_{\min }\left(\mathrm{e} \AA^{-3}\right)$ & $0.34,-0.30$ & $0.22,-0.26$ \\
\hline Extinction method & SHELXL97 & $\begin{array}{l}\text { Becker-Coppens } \\
\text { Lorentzian model }\end{array}$ \\
\hline Extinction coefficient & $0.076(9)$ & 1.03 \\
\hline
\end{tabular}

Computer programs used: SMART (Siemens, 1995), SXD (Keen \& Wilson, 1996), SAINT (Siemens, 1995), SADABS (Sheldrick, 2002), SHELXS97 (Sheldrick, 1997), SHELXL97 (Sheldrick, 1997), DIAMOND (Brandenburg, 2000), PLATON (Spek, 2003).

of-flight diffraction data, allied with quantum chemistry calculations carried out using DFT methods. This approach allows the estimation of the shifts of the basic $\mathrm{O}-\mathrm{H}$ and $\mathrm{C}-\mathrm{H}$ stretching frequencies resulting from the formation of hydrogen bonds. This procedure has to date been carried out only rarely using the powerful combination of neutron diffraction and high-level quantum calculations.

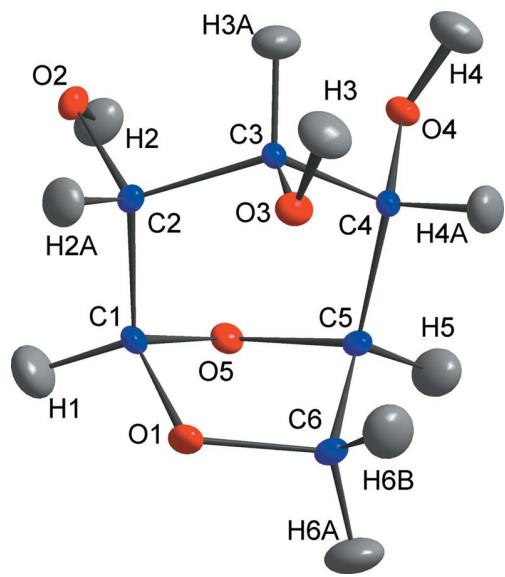

Figure 1

Displacement ellipsoid drawing of the molecule of the title compound with the atomic numbering scheme (neutron data). The ellipsoids are drawn at the $50 \%$ probability level.

\section{Experimental and calculation}

Levoglucosan was prepared by the thermodegradation of starch at very low pressure according to the slightly modified procedure described by Épshtein et al. (1959). Colourless crystals of reasonable quality were obtained by slow crystallization from ethanol. To obtain a better definition of the sugar ring geometry the structure was first re-refined from newly collected low-temperature X-ray data. In this refinement the $\mathrm{H}$ atoms were refined constrained to ideal geometries using an appropriate riding model. For tertiary $\mathrm{H}$ atoms, the $\mathrm{C}-\mathrm{H}$ distance was kept fixed at $1.00 \AA$ and for secondary $\mathrm{H}$ atoms at $0.99 \AA$. For the hydroxyl groups, the $\mathrm{O}-\mathrm{H}$ distance $(0.84 \AA)$ and $\mathrm{C}-\mathrm{O}-\mathrm{H}$ angle $\left(109.5^{\circ}\right)$ were kept fixed, while the torsion angle was allowed to refine, with the starting position based on a circular Fourier synthesis.

Neutron diffraction data were collected at $100 \mathrm{~K}$ on the SXD instrument at the ISIS spallation neutron source (Keen et al., 2006) using the time-of-flight Laue diffraction method (Keen \& Wilson, 1996; Wilson, 1997). The intensities were extracted and reduced to structure factors using standard SXD procedures (Wilson, 1997) and structure refinement carried out using SHELXL97 (Sheldrick, 1997). All atoms were refined with anisotropic displacement parameters, without any constraints, starting from the coordinates from the lowtemperature X-ray refinement. The crystal data, data collection details and structure refinement parameters are presented in Table 1; the atomic coordinates have been deposited. ${ }^{\mathbf{1}}$ The numbering scheme used to describe the molecule, together with atomic displacement ellipsoids resulting from refinement against the neutron data, is shown in Fig. 1; the important bond lengths are summarized in Table 2. The absolute configuration at chiral atoms $\mathrm{C} 1, \mathrm{C} 2, \mathrm{C} 3, \mathrm{C} 4$ and $\mathrm{C} 5$ was assigned on the basis of the known arrangement in the $\beta$-Dglucopyranose moiety.

\footnotetext{
${ }^{1}$ Supplementary data for this paper are available from the IUCr electronic archives (Reference: BS5034). Services for accessing these data are described at the back of the journal.
} 
Table 2

Selected interatomic distances $d(\AA)$ in levoglucosan obtained from both refinements and the differences $\left(\times 10^{3}\right) d$ (neutron) - $d$ (structure optimizations in the solid state).

$\Delta_{1}$ without and $\Delta_{2}$ with the cell optimization. The ring bond angles are not reported, because they lie in a narrow interval with the mean difference $\sim 0.3^{\circ}$.

\begin{tabular}{lllll}
\hline & X-ray & Neutron & $\Delta_{1}$ & $\Delta_{2}$ \\
\hline O1-C1 & $1.4364(14)$ & $1.428(4)$ & -17 & -15 \\
O1-C6 & $1.4514(14)$ & $1.455(4)$ & -3 & -4 \\
O2-C2 & $1.4296(12)$ & $1.425(3)$ & -8 & -9 \\
O3-C3 & $1.4331(12)$ & $1.429(3)$ & -5 & -6 \\
O4-C4 & $1.4366(12)$ & $1.430(3)$ & -7 & -6 \\
O5-C1 & $1.4133(14)$ & $1.415(3)$ & -2 & -1 \\
O5-C5 & $1.4512(13)$ & $1.447(4)$ & -5 & -6 \\
C1-C2 & $1.5298(14)$ & $1.532(3)$ & 0 & 0 \\
C2-C3 & $1.5452(14)$ & $1.549(3)$ & 2 & 2 \\
C3-C4 & $1.5492(14)$ & $1.547(3)$ & -4 & -3 \\
C4-C5 & $1.5215(14)$ & $1.527(3)$ & 2 & 2 \\
C5-C6 & $1.5310(15)$ & $1.532(3)$ & 2 & 2 \\
\hline
\end{tabular}

The isolated molecule $a b$ initio calculations were performed using the GAMESS program package (Schmidt et al., 1993). The starting atomic coordinates were taken from the final neutron refinement cycle and geometry optimization carried out at the B3LYP/6-31+G* level of theory. Convergence in the calculation was assumed to be reached when the total energy change between two consecutive self-consistent field (SCF) cycles was less than $10^{-5}$ a.u. Final atomic coordinates were used in a vibrational frequency calculation run employing the dynamic matrix formalism, applying static atom displacements of $0.01 \AA$. Calculated eigenvectors and eigenfrequencies were used to calculate the vibrational density of states.

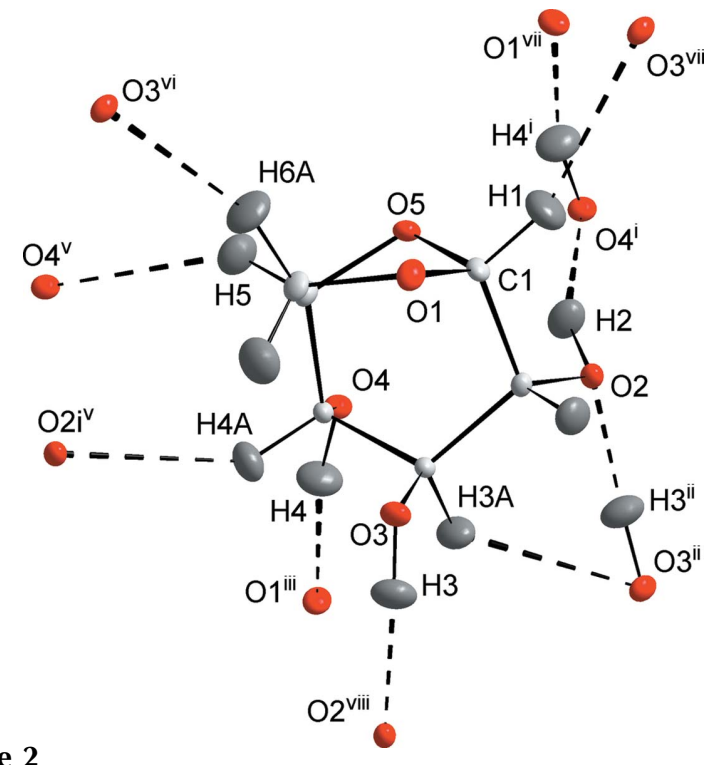

Figure 2

$\mathrm{O}-\mathrm{H} \cdots \mathrm{O}$ intermolecular bond scheme in levoglucosan (neutron data). The ellipsoids are drawn at the $50 \%$ probability level. [Symmetry codes: (i) $\frac{1}{2}+x, \frac{1}{2}-y, 1-z$; (ii) $\frac{1}{2}+x, \frac{1}{2}-y,-z$; (iii) $-x, \frac{1}{2}+y, \frac{1}{2}-z$; (iv) $-1+x, y$, $z ;$ (v) $-\frac{1}{2}+x, \frac{1}{2}-y, 1-z$; (vi) $-\frac{1}{2}-x,-y, \frac{1}{2}+z$; (vii) $\frac{1}{2}-x,-y, \frac{1}{2}+z$; (viii) $-\frac{1}{2}+x, \frac{1}{2}-y,-z$.] The sequence of fundamental $\mathrm{O}-\mathrm{H} \cdots \mathrm{O}$ interactions $\left[\mathrm{O} 3(\mathrm{H})^{\mathrm{1}} \cdots \mathrm{O} 2(\mathrm{H}) \cdots \mathrm{O} 4(\mathrm{H})^{\mathrm{i}} \cdots \mathrm{O} 1^{\text {viii }}\right]$ is portrayed on the right-hand side. Labels of some atoms not involved in hydrogen bonding have been omitted for the sake of clarity.
Solid-state (periodic) calculations were performed using the Vienna ab initio simulation package VASP (Kresse \& Hafner, 1993; Kresse \& Furthmüller, 1996). In this package the exchange-correlation functional is expressed in the localized density approximation (LDA; Perdew \& Zunger, 1981), together with the generalized gradient approximation (GGA; Perdew \& Wang, 1992). Plane waves form a basis set and calculations are performed using the projector-augmented wave (PAW) method (Blöchl, 1994; Kresse \& Joubert, 1999) and atomic pseudo-potentials (Kresse \& Hafner, 1994). An optional energy cutoff controlling the accuracy of the calculation was set to $500 \mathrm{eV}$, representing a very extended basis set and consequent highly accurate calculations. The Brillouinzone sampling was restricted to the $\Gamma$ point. On relaxation, the positions of all atoms were optimized by applying the conjugate gradient until the differences in total energy were less than $10^{-5} \mathrm{eV}$. No symmetry restrictions were applied during the geometry optimization; the structure optimization was thus effectively performed in the $P 1$ space group. The fourfold redundancy of atomic coordinates in this configuration served for an internal check of the consistency of the calculations. The converged structure was used in frequency calculations using the same procedure as mentioned above.

\section{Results and discussion}

\subsection{Geometrical analysis}

The interatomic distances derived from our X-ray refinement (Table 2) are typically around 2-3o longer than the original values obtained by Park et al. (1971) from roomtemperature data. Analysis of relevant torsion angles and puckering parameters (Cremer \& Pople, 1975) indicates (i) that the O5/C1-C5 pyranose ring in levoglucosan adopts a ${ }^{1} C_{4}$ conformation slightly distorted to the $E_{\mathrm{O}}$ direction and (ii) an almost ideal $E_{2}\left(E_{\mathrm{O} 5}\right)$ conformation for the five-membered 1,3-dioxolane ring.

A summary of the geometry of the hydrogen bonds, uncorrected for librational effects, is given in Table 3 (based on the neutron diffraction data). The levoglucosan molecules are linked into finite chains $[\mathrm{O} 3(\mathrm{H}) \cdots \mathrm{O} 2(\mathrm{H}) \cdots \mathrm{O} 4(\mathrm{H}) \cdots \mathrm{O} 1]$ formed by strong $\mathrm{O}-\mathrm{H} \cdots \mathrm{O}$ hydrogen bonds with $d(\mathrm{O} \cdots \mathrm{O})<$ $2.8 \AA$ (Fig. 2). In this chain, atom $\mathrm{O} 4$ is seen to act as both donor and acceptor of hydroxyl $\mathrm{H}$ atoms in the chain, while atom $\mathrm{O} 3$ is a donor to $\mathrm{O} 2$ and the non-hydroxyl atom $\mathrm{O} 1$ terminates the chain (Jeffrey \& Mitra, 1983). These hydrogen bonds can be categorized as 'cooperative bonds' (Ceccarelli et al., 1981). There is also a bifurcated three-centre hydrogen bond $\mathrm{O} 2(\mathrm{H}) \cdots(\mathrm{O} 4, \mathrm{O} 5)$ present in the structure, consisting of

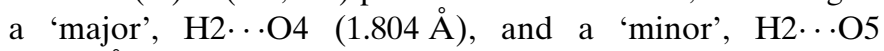
$(2.473 \AA)$, component. Although somewhat longer, the $\mathrm{H} 2 \cdots \mathrm{O} 5$ separation is well within the limit for the minor components in such bonds proposed by Jeffrey \& Mitra (1983). The bond angles within the bifurcated three-centre bond fit well to the major and minor regions of the $\mathrm{O}-\mathrm{H} \cdots \mathrm{O}$ bond angle versus $d(\mathrm{H} \cdots \mathrm{O})$ distance distributions reported for carbohydrates (Steiner \& Saenger, 1992a). In graph-set 
Table 3

Summary of hydrogen-bond geometry $\left(\AA,^{\circ}\right)$ in levoglucosan.

Differences in distances and angles $X$ (neutron) $-X$ (structure optimizations in solid state) are in the second (fixed cell) and the third rows (optimized cell), respectively. The differences in distances are $\times 10^{3}$.

\begin{tabular}{|c|c|c|c|c|c|}
\hline & $D-\mathrm{H}$ & $\mathrm{H} \cdots A$ & $D \cdots A$ & $D-\mathrm{H} \cdots A$ & Label \\
\hline \multirow[t]{3}{*}{$\mathrm{O} 2-\mathrm{H} 2 \cdots \mathrm{O} 5$} & $0.989(6)$ & $2.473(7)$ & $2.880(4)$ & $104.2(4)$ & $b$ \\
\hline & -13 & -75 & -48 & 2.0 & \\
\hline & -10 & -46 & -34 & 1.0 & \\
\hline \multirow[t]{3}{*}{$\mathrm{O} 2-\mathrm{H} 2 \cdots \mathrm{O} 4^{\mathrm{i}}$} & $0.989(6)$ & $1.804(6)$ & $2.735(3)$ & $155.7(6)$ & $a$ \\
\hline & -13 & 76 & 47 & -3.5 & \\
\hline & -10 & 52 & 26 & -3.5 & \\
\hline \multirow[t]{3}{*}{$\mathrm{O} 3-\mathrm{H} 3 \cdots \mathrm{O} 2^{\mathrm{ii}}$} & $0.969(7)$ & 1.799 (7) & $2.754(3)$ & $168.2(6)$ & $c$ \\
\hline & -27 & 73 & 38 & -3.7 & \\
\hline & -26 & 63 & 31 & -2.7 & \\
\hline \multirow{3}{*}{$\mathrm{O} 4-\mathrm{H} 4 \cdots \mathrm{O} 1^{\mathrm{iii}}$} & $0.978(6)$ & $1.801(6)$ & $2.755(3)$ & $164.2(7)$ & $d$ \\
\hline & -15 & 44 & 25 & -1.0 & \\
\hline & -15 & 49 & 35 & 0.3 & \\
\hline \multirow[t]{3}{*}{$\mathrm{C} 6-\mathrm{H} 6 B \cdots \mathrm{O} 3$} & $1.093(8)$ & $2.526(8)$ & $2.999(4)$ & $104.9(5)$ & \\
\hline & -2 & -14 & -39 & -1.6 & \\
\hline & 3 & -26 & -35 & -0.6 & \\
\hline \multirow[t]{3}{*}{$\mathrm{C} 1-\mathrm{H} 1 \cdots \mathrm{O} 3^{\mathrm{vii}}$} & $1.097(8)$ & $2.565(9)$ & $3.606(3)$ & $158.0(6)$ & \\
\hline & -1 & -51 & -59 & -1.4 & \\
\hline & -4 & -11 & -13 & 0.3 & \\
\hline \multirow[t]{3}{*}{$\mathrm{C} 3-\mathrm{H} 3 A \cdots \mathrm{O} 3^{\mathrm{viii}}$} & $1.112(6)$ & $2.565(7)$ & $3.459(3)$ & $136.6(5)$ & \\
\hline & 12 & 128 & 71 & -7.3 & \\
\hline & 11 & -2 & 13 & 0.5 & \\
\hline \multirow{3}{*}{$\mathrm{C} 4-\mathrm{H} 4 A \cdots \mathrm{O} 2^{\mathrm{iv}}$} & $1.113(6)$ & $2.447(6)$ & $3.420(3)$ & $145.3(5)$ & \\
\hline & 18 & -29 & 11 & 2.8 & \\
\hline & 10 & .22 & 22 & -0.9 & \\
\hline \multirow[t]{3}{*}{$\mathrm{C} 5-\mathrm{H} 5 \cdots \mathrm{O}^{v}$} & $1.101(7)$ & $2.477(7)$ & $3.419(4)$ & $142.9(5)$ & \\
\hline & 3 & 38 & -79 & -18.8 & \\
\hline & 6 & -26 & -18 & 0.4 & \\
\hline \multirow[t]{3}{*}{$\mathrm{C} 6-\mathrm{H} 6 A \cdots \mathrm{O} 3^{\mathrm{vi}}$} & $1.111(8)$ & $2.411(8)$ & $3.464(4)$ & $157.5(6)$ & \\
\hline & 10 & -122 & 50 & 21.3 & \\
\hline & 14 & -39 & -28 & -0.6 & \\
\hline
\end{tabular}

Symmetry codes: (i) $\frac{1}{2}+x, \frac{1}{2}-y, 1-z$; (ii) $-\frac{1}{2}+x, \frac{1}{2}-y,-z$; (iii) $-x, \frac{1}{2}+y, \frac{1}{2}-z$; (iv) $-1+x, y, z$; (v) $-\frac{1}{2}+x, \frac{1}{2}-y, 1-z$; (vi) $-\frac{1}{2}-x,-y, \frac{1}{2}+z$; (vii) $\frac{1}{2}-x,-y, \frac{1}{2}+z$; (viii) $\frac{1}{2}+x, \frac{1}{2}-y,-z$.

notation (Bernstein et al., 1995; Grell et al., 1999), there are four first-level interactions: $(a) C(6)$ intramolecular hydrogenbond chains (hydrogen-bond labelling defined in Table 3); (b) $S(5)$ intramolecular strings; $(c) C(5)$ chains and $(d) C(6)$ chains. At the second level, there are chains $C_{2}^{2}(7)$ and $C_{2}^{2}(11)$ for $(a)$ and $(c), C_{2}^{2}(7)$ and $C_{2}^{2}(12)$ for $(a)$ and $(d)$, and, finally, $C_{2}^{2}(12)$ and $C_{2}^{2}(10)$ for $(c)$ and $(d)$ hydrogen bonds. The assignment of graph-set descriptors was performed using PLUTO (Motherwell et al., 1999).

The hydrogen-bond pattern is completed by weak $\mathrm{C}-$ $\mathrm{H}$... O intermolecular contacts (Table 3). A basic statistical analysis of these interactions in carbohydrates was presented by Steiner \& Saenger (1992b), who analysed the geometrical characteristics of $\mathrm{C}-\mathrm{H} \cdots \mathrm{O}$ hydrogen bonds extracted from 30 neutron diffraction studies. The geometries of the weak $\mathrm{C}-$ $\mathrm{H}$... O interactions found in levoglucosan fit well to the distributions found by Steiner \& Saenger (1992b). This comprises a unimodal distribution of $\mathrm{H}$... O distances with a mode of $\sim 2.5 \AA$, and a bimodal distribution of $\mathrm{C} \cdots \mathrm{O}$ distances with one narrow component (centred around $\sim 2.9 \AA$ ) reflecting the distribution of intramolecular C... distances and a broad component (spanning $\sim 3.1$ to $\sim 3.8 \AA$ ) reflecting the large flexibility of $\mathrm{C}-\mathrm{H} \cdots \mathrm{O}$ bonds. In levo- glucosan, the intramolecular $\mathrm{C} 6-\mathrm{H} 6 \mathrm{~B} \cdots \mathrm{O} 3$ interaction belongs to the first category, and the remainder to the second. The $d(\mathrm{C} \cdots \mathrm{O})$ distances and related $\alpha(\mathrm{C}-\mathrm{H} \cdots \mathrm{O})$ angles for these intermolecular contacts are not correlated; the correlation scatter plot presented by Steiner \& Saenger (1992b) also indicated that the distance versus $\alpha(\mathrm{C}-\mathrm{H} \cdots \mathrm{O})$ angle dependence showed no clear tendency to clustering within the region of interest. As the $\mathrm{C}-\mathrm{H} \cdots \mathrm{O}$ bonds are only moderately bent, it can be assumed that interaction energy of $\mathrm{C}-$ $\mathrm{H}$... O bonds is dominated by its electrostatic part (Steiner \& Desiraju, 1998). A more recent study (Gatti et al., 2002) of fundamental properties of $\mathrm{C}-\mathrm{H}$. . O hydrogen bonds in the crystal structure of 3,4-bis(dimethylamino)-3-cyclobutene-1,2dione, where no competing stronger $\mathrm{O}-\mathrm{H} \cdots \mathrm{O}$ interactions are present, showed a clear distinction between bonded and non-bonded $\mathrm{C}-\mathrm{H}$... O contacts. While 23 unique 'bonded' $\mathrm{C}-\mathrm{H}$... O contacts were characterized by nearly constant $\left(\sim 140^{\circ}\right) \mathrm{C}-\mathrm{H} \cdots \mathrm{O}$ angles, the contacts with 'non-bonded' $\mathrm{H}$... O separations of up to $3 \AA$ can have this angle narrowed to $90^{\circ}$. These different values point to the prevalence of electrostatic contributions to the interaction energy in the former, and of van der Waals contributions in the latter case. The larger flexibility of the $\alpha(\mathrm{C}-\mathrm{H} \cdots \mathrm{O})$ angle, even in the bonded case, has been explained by $\mathrm{Gu}$ et al. (1999) on the basis of the lower energetic costs of bending the $\mathrm{C}-\mathrm{H} \cdots \mathrm{O}$ bond compared with the stronger $\mathrm{O}-\mathrm{H} \cdots \mathrm{O}$ bonds.

\subsection{DFT calculations}

Single crystal neutron diffraction refinements provide the benchmark measure of accuracy for hydrogen-bond geometries obtained by ab initio optimization; this allows to evaluate the ability of $a b$ initio computations to treat weaker bonds with very low binding energies to be evaluated. Unfortunately, $a b$ initio solid-state calculations of hydrogen bonds are still far from being routine, the main reason being that the accuracy of relatively less time-consuming Hartree-Fock calculations is not sufficient for the correct description of weak interactions; inclusion of correlation effects is therefore necessary. As there is currently no generally accepted limit for solid-state calculations, we note that for isolated molecule calculations the MP2/6-31+G $(d, p)$ level of theory has been identified as the minimum level required to obtain reliable geometries (Del Bene \& Jordan, 2001). This work also stressed that to obtain reliable interaction energies still larger basis sets should typically be used. Calculations at this level of theory in the solid-state environment present a significant computational task for structures of the complexity of levoglucosan and have to date rarely been employed. In light of this, less computationally intensive DFT methods are frequently used, on the assumption that their accuracy is competitive with classical MP2 methods (Calhorda, 2000). However, it is known that weak interactions are not well modelled in DFT methods, and every case should be considered separately and with caution.

In the first set of DFT calculations carried out here, all atomic positions were optimized by $V A S P$ with respect to minimizing interatomic forces, keeping the cell parameters 
fixed to the experimentally determined values. Upon convergence the total energy dropped from the value of $-497.63160 \mathrm{eV}$ obtained in a single point calculation for the refined structure to the more favourable value of $-497.85672 \mathrm{eV}$. Although the calculation was carried out in space group $P 1$, no significant deviations from the orthorhombic symmetry found in the crystal structure were detected. A comparison of experimentally determined and DFT-calculated distances between covalently bonded non-H atoms shows excellent agreement; all differences are $\leq 3 \sigma$ of the distances determined from the neutron refinement (Table 2). Similarly, an examination of the $\mathrm{O}-\mathrm{H}(\mathrm{C}-\mathrm{H})$ bond distances revealed that their accuracy is in keeping with the limits inherent to this type of calculation $(\sim 0.01-0.02 \AA)$, the largest deviations being $0.023 \AA$ for $\mathrm{O} 3-\mathrm{H} 3$ and $0.018 \AA$ for $\mathrm{C} 4-\mathrm{H} 4 A$. The $\mathrm{H} \cdots \mathrm{O}$ and $\mathrm{O} \cdots \mathrm{O}$ separations in the strong hydrogen bonds are found to be in very good agreement with the refined values, with the relative errors in calculated $\mathrm{O}-$ $\mathrm{H} \cdots \mathrm{O}$ bond angles also very similar to those of the bond distances.

In contrast, for the weaker $\mathrm{C}-\mathrm{H} \cdots \mathrm{O}$ intermolecular contacts considerably larger discrepancies between experimental and calculated bond angles are found. The most noticeable deviations from the experimentally determined values are $\mathrm{C} 6-\mathrm{H} 6 A \cdots \mathrm{O}^{\mathrm{vi}}\left(\Delta=-21.32^{\circ}\right), \mathrm{C} 5-\mathrm{H} 5 \cdots \mathrm{O} 4^{\mathrm{v}}$ $\left(\Delta=18.78^{\circ}\right)$ and $\mathrm{C} 3-\mathrm{H} 3 A \cdots \mathrm{O} 3^{\text {viii }}\left(\Delta=7.3^{\circ}\right)$ (symmetry codes as in Table 3). The changes in bond angles are also reflected in changes in contact distances, e.g. by the lengthening of the $\mathrm{H} 6 A \cdots \mathrm{O} 3^{\mathrm{vi}}$ distance by as much as $0.12 \AA$ and the shortening of the $\mathrm{C} 6 \cdots \mathrm{O}^{\mathrm{vi}}$ distance by $0.05 \AA$. The positive deviation of the $\mathrm{C} 3-\mathrm{H} 3 A \cdots \mathrm{O} 3^{\text {viii }}$ angle from the experimentally determined value is also reflected in the shortening of the $\mathrm{C} 3 \cdots \mathrm{O} 3^{\text {viii }}$ distance by $0.13 \AA$. These differences all exceed the estimated precision of the values determined from the computational method and may point to some deficiency in the calculations.

To investigate this issue further, we have also carried out DFT calculations involving optimization of the unit cell. Frequently, when there is a large discrepancy between the structural geometry accurately determined by experiment and by energy minimization, it is stated that the experimentally determined structure does not correspond to the global energetic minimum. In reality, though, the calculated structure need not itself represent the true global minimum, but simply the minimum reachable by the computational method used within a given set of parameters. In the case of solid-state calculations a standard remedy to the problem of such inaccurate geometries is a 're-optimization' ('relaxation') of cell parameters followed by a new structure optimization. Such a process is expected to lead, if not to a global minimum, then at least to a lower value of the total energy, resulting in a more stable configuration and more accurate geometric characteristics. Thus, in addressing the accuracy of the geometries of the $\mathrm{C}-\mathrm{H} \cdots \mathrm{O}$ bonds found here, a new series of calculations was performed, where the cell parameters were first relaxed keeping the atomic position fixed, and then the atomic positions were optimized with the cell parameters fixed to the values obtained from the previous run. The whole procedure was repeated three times, resulting in a total energy of $-497.78676 \mathrm{eV}$, indicating that such a structure is actually less stable than that obtained from the optimization within the unit cell fixed at the experimental value. The final values of the computationally optimized cell parameters $a, b$ and $c$ were found to be $0.033,0.021$ and $0.091 \AA$ smaller, respectively, than those obtained from the neutron diffraction experiment. An inspection of the differences in the $\mathrm{C}-\mathrm{C}, \mathrm{C}-\mathrm{O}, \mathrm{O}-\mathrm{H}$ and $\mathrm{C}-\mathrm{H}$ bond distances shows that optimization of the cell parameters had only a small effect on their values, i.e. the covalent bonds were not affected. Nor were there any significant changes in the geometry of $\mathrm{O}-\mathrm{H} \cdots \mathrm{O}$ bonds (Table 3 ). As anticipated, the most noticeable variations are the changes in $\mathrm{C}-\mathrm{H} \cdots \mathrm{O}$ bond angles, which are closer to the experimental values despite the higher total energy obtained for this optimized structure. However, the choice of which calculation to accept should in this case be resolved in favour of total energy and the conclusion made that at this level of theory we have most probably reached the current limit of the method. Some more light can be shed on the problem by referring to the computational study of Gu et al. (1999), who studied C$\mathrm{H} \cdots \mathrm{O}$ geometries in several clusters at high levels of theory (MP2, MP4, CCSD). In that work it was found that a change in $\alpha(\mathrm{C}-\mathrm{H} \cdots \mathrm{O})$ angle in a hydrogen-bonded $\mathrm{H}_{3} \mathrm{CH} \cdots \mathrm{OH}_{2}$ system by $\pm 20^{\circ}$ destabilizes the system only by $\sim 0.2 \mathrm{kcal} \mathrm{mol}^{-1}$. Considering this value and recalling the $\mathrm{C}-$ $\mathrm{H} \cdots \mathrm{O}$ bond angles summarized in Table 3 we can conclude that while the $\mathrm{C}-\mathrm{H} \cdots \mathrm{O}$ contacts have the same tendency to linearity as 'conventional' $\mathrm{O}-\mathrm{H} \cdots \mathrm{O}$ bonds, they are by no means as sensitive to angular deformations.

The optimized molecular and crystal structures resulting from the calculations outlined above were used to calculate vibrational densities of states. This allows the changes in basic stretching $\mathrm{OH}$ and $\mathrm{CH}$ frequencies caused by the combination of hydrogen-bond formation and the crystal field to be determined. The calculated dipole moment of the molecule with the geometry determined directly from the crystal structure is $\sim 4 \mathrm{D}$. The calculated differences in stretching frequencies are shown in Fig. 3. It is widely accepted that formation of $\mathrm{O}-\mathrm{H} \cdots \mathrm{O}$ hydrogen bonds results in a weakening of the $\mathrm{O}-\mathrm{H}$ covalent bonds involved, leading to an associated decrease - a red shift - in stretching frequencies compared with those calculated for a molecule in vacuo. The shifts documented in the literature range from tens to hundreds of $\mathrm{cm}^{-1}\left(\sim 0.1-1 \mathrm{~kJ} \mathrm{~mol}^{-1}\right)$. This picture is in accord with the shifts found here (Fig. 3, left). The largest shift was obtained for the $\mathrm{O} 2-\mathrm{H} 2$ bond, which is involved in a bifurcated hydrogen bond, agreeing with the fact that the strength of a hydrogen bond and size of the frequency shift are correlated. The absence of geometric evidence for different values of the shifts for the $\mathrm{O} 3-\mathrm{H} 3$ and $\mathrm{O} 4-\mathrm{H} 4$ covalent bonds can be attributed to the current limits of the calculation methods used. A similar trend in shifts has been experimentally determined by polarized IR spectra recorded from a single crystal of the related compound $\beta$-D-fructopyranose (Baran et al., 1994). 
Of perhaps more interest is the fact that our calculations predict blue shifts of $\mathrm{C}-\mathrm{H}$ stretching frequencies (Fig. 3, right). This phenomenon is not yet as widely accepted as its red shift counterpart and has been mostly studied on a range of model systems by various computational methods ( $\mathrm{Gu}$ et al., 1999; Hobza \& Havlas, 2000; Kovács et al., 2002; Scheiner \& Kar, 2002; Castellano, 2004). The nature of this effect is not yet fully understood, but a possible mechanism has been proposed (Hermansson, 2002). Considering the level of theory used in this work and the lack of relevant literature for a comparison we cannot necessarily rely upon the exact values of the individual shifts found here. However, it is likely that the consistent shift of $\mathrm{C}-\mathrm{H}$ vibrations towards higher frequencies is related to the formation of hydrogen bonds and the effect of the crystal field polarity. It is also noteworthy that the magnitudes of the blue shifts indicated are not seriously influenced by cell optimization, i.e. by the changes in $\mathrm{C}-$ $\mathrm{H}$. . O bond angles.

\section{Conclusion}

The analysis of relevant torsion angles and puckering parameters in the geometry of levoglucosan shows that the pyranose ring in levoglucosan adopts a ${ }^{1} C_{4}$ conformation slightly distorted to the $E_{\mathrm{O}}$ direction. The levoglucosan molecules are linked into finite chains formed by strong $\mathrm{O}-\mathrm{H} \cdots \mathrm{O}$ hydrogen bonds with $d(\mathrm{O} \cdots \mathrm{O})<2.8 \AA$. A bifurcated three-centre hydrogen bond, $\mathrm{O} 2(\mathrm{H}) \cdots(\mathrm{O} 4, \mathrm{O} 5)$, present in the structure consists of a well defined 'major' and a 'minor' component, as frequently found in such cases. A comparison of experimentally determined and DFT-calculated distances between covalently bonded non-H atoms shows excellent agreement; all differences are $\leq 3 \sigma$ of the distances from the neutron refinement. Similarly, an examination of the $\mathrm{O}-\mathrm{H}(\mathrm{C}-\mathrm{H})$ covalent bond distances shows that their accuracy is in keeping with the limits inherent to this type of calculation. Differences in $\mathrm{H} \cdots \mathrm{O}$ and $\mathrm{O} \cdots \mathrm{O}$ separations within the strong $\mathrm{O}-\mathrm{H} \cdots \mathrm{O}$ hydrogen bonds are also found to be in very good

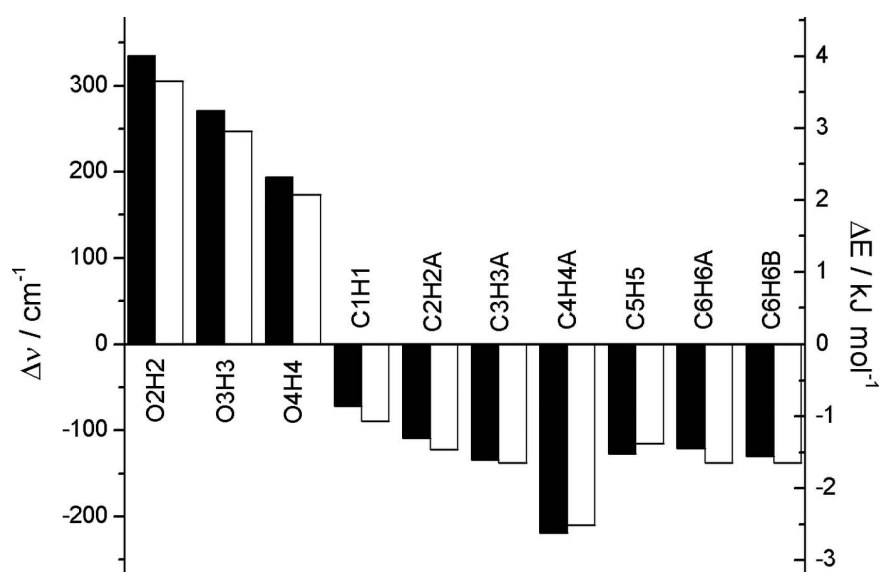

Figure 3

Changes in basic stretching frequencies calculated as $v$ (molecule) $v$ (crystal). Filled bars: calculation with experimentally determined cell parameters; empty bars: calculation with optimized cell parameters. agreement with the refined values, while the relative errors in the calculated $\mathrm{O}-\mathrm{H} \cdots \mathrm{O}$ bond angles are very similar to those of the bonding distances. In contrast, for the weaker $\mathrm{C}-$ $\mathrm{H}$... O intermolecular contacts, considerably larger discrepancies between experimental and calculated bond angles were obtained. These differences all exceeded the estimated precision of the values determined from the computational method and could point to some deficiency in the calculations.

Vibrational densities of states were calculated in order to determine the changes in basic stretching $\mathrm{OH}$ and $\mathrm{CH}$ frequencies caused by the combination of hydrogen-bond formation and the effect of crystal field. The results from our calculations are in agreement with the widely accepted assumption that formation of $\mathrm{O}-\mathrm{H} \cdots \mathrm{O}$ bonds results in a weakening of the $\mathrm{O}-\mathrm{H}$ covalent bonds involved, leading to an associated decrease - a red shift - in stretching frequencies, by typically tens to hundreds of $\mathrm{cm}^{-1}$. The largest shift is obtained for the $\mathrm{O} 2-\mathrm{H} 2$ bond, which is involved in a bifurcated hydrogen bond. The calculations also predict significant blue shifts of $\mathrm{C}-\mathrm{H}$ stretching frequencies. While we cannot rely on the exact values of the shifts calculated here, the consistent shift of $\mathrm{O}-\mathrm{H}$ vibrations towards lower and $\mathrm{C}-\mathrm{H}$ vibrations towards higher frequencies is likely to be related to the formation of hydrogen bonds and the effect of the crystal field polarity.

This work was partially supported by Slovak Grant Agency VEGA under the contract 2/6178/26. Neutron beamtime on the SXD instrument was provided by CCLRC-ISIS, UK. LS and MS are indebted to Professor J. Hafner for providing them with a copy of the program $V A S P$.

\section{References}

Baran, J., Ratajczak, H., Lutz, E. T. G., Verhaegh, N., Luinge, H. J. \& van der Maas, J. H. (1994). J. Mol. Struct. 326, 109-122.

Bernstein, J., Davis, R. E., Shimoni, L. \& Chang, N.-L. (1995). Angew. Chem. Int. Ed. Engl. 34, 1555-1573.

Blöchl, P. E. (1994). Phys. Rev. B, 50, 17953-17979.

Brandenburg, K. (2000). DIAMOND, Version 2.1.d. Crystal Impact GbR, Bonn, Germany.

Calhorda, M. J. (2000). Chem. Commun. pp. 801-809.

Castellano, R. K. (2004). Curr. Org. Chem. 8, 845-865.

Ceccarelli, C., Jeffrey, G. A. \& Taylor, R. (1981). J. Mol. Struct. 70, 255-271.

Cremer, D. \& Pople, J. A. (1975). J. Am. Chem. Soc. 97, 1354-1358.

Del Bene, J. E. \& Jordan, M. J. T. (2001). J. Mol. Struct. (Theochem), 573, 11-23.

Épshtein, Ya. V., Golova, O. P. \& Durynina, L. I. (1959). Russ. Chem. Bull. 8, 1089-1090.

Gatti, C., May, E., Destro, R. \& Cargnoni, F. (2002). J. Phys. Chem. A, 106, 2707-2720.

Grell, J., Bernstein, J. \& Tinhofer, G. (1999). Acta Cryst. B55, 1030 1043.

Gu, Y., Kar, T. \& Scheiner, S. (1999). J. Am. Chem. Soc. 121, 94119422.

Hermansson, K. (2002). J. Phys. Chem. A, 106, 4965-4702.

Hobza, P. \& Havlas, Z. (2000). Chem. Commun. pp. 4253-4264.

Jeffrey, G. A. \& Mitra, J. (1983). Acta Cryst. B39, 469-480.

Keen, D. A., Gutmann, M. J. \& Wilson, C. C. (2006). J. Appl. Cryst. 39, $714-722$. 
Keen, D. A. \& Wilson, C. C. (1996). Technical Report RAL-TR-96083. Rutherford Appleton Laboratory, Chilton, Didcot, Oxon, UK.

Kovács, A., Szabó, A., Nemcsok, D. \& Hargittai, I. (2002). J. Phys. Chem. A, 106, 5671-5678.

Kresse, G. \& Furthmüller, (1996). J. Comput. Mater. Sci. 6, 15-50.

Kresse, G. \& Hafner, J. (1993). Phys. Rev. B, 48, 13115-13118.

Kresse, G. \& Hafner, J. (1994). J. Phys. Condens. Matter, 6, 82458527.

Kresse, G. \& Joubert, D. (1999). Phys. Rev. B, 59, 1758-1775.

Motherwell, W. D. S., Shields, G. P. \& Allen, F. H. (1999). Acta Cryst. B55, 1044-1056.

Park, Y. J., Kim, H. S. \& Jeffrey, G. A. (1971). Acta Cryst. B27, 220 227.

Perdew, J. P. \& Wang, Y. (1992). Phys. Rev. B, 45, 13244-13249.

Perdew, J. P. \& Zunger, A. (1981). Phys. Rev. B, 23, 5048-5079.

Scheiner, S. \& Kar, T. (2002). J. Phys. Chem. A, 106, 1784-1789.
Schmidt, M. W., Baldridge, K. K., Boatz, J. A., Elbert, S. T., Gordon, M. S., Jenses, J. H., Koseki, S., Matsunaga, N., Nguyen, K. A., Su, S., Windus, T. L., Dupuis, M. \& Motgomery, J. A. Jr (1993). J. Comput. Chem. 14, 1347-1363.

Sheldrick, G. M. (1997). SHELXL97. University of Göttingen, Germany.

Sheldrick, G. M. (2002). SADABS. Version 2.03. University of G̈ottingen, Germany.

Siemens (1995). SMART and SAINT. Siemens Analytical X-ray Instruments Inc., Madison, Wisconsin, USA.

Spek, A. L. (2003). J. Appl. Cryst. 36, 7-13.

Steiner, T. \& Desiraju, G. R. (1998). Chem. Commun. pp. 891-892.

Steiner, T. \& Saenger, W. (1992a). Acta Cryst. B48, 819-827.

Steiner, T. \& Saenger, W. (1992b). J. Am. Chem. Soc. 114, 1014610154.

Wilson, C. C. (1997). J. Mol. Struct. 405, 207-217. 